\title{
Host Specificity of Amblyomma cajennense (Fabricius, 1787) (Acari: Ixodidae) with Comments on the Drop-off Rhythm
}

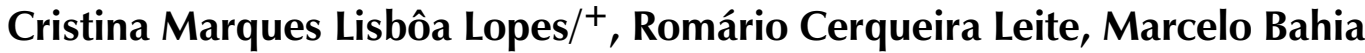 \\ Labruna*, Paulo Roberto de Oliveira, Lígia Miranda Ferreira Borges**, Zénon \\ Batista Rodrigues, Henrique Ávila de Carvalho, Carolina Maria Vianna de \\ Freitas, Carlos Roberto Vieira Júnior
}

Departamento de Medicina Veterinária Preventiva, Escola de Veterinária, Universidade Federal de Minas Gerais, Av. Antônio Carlos 6627, 30161-970 Belo Horizonte, MG, Brasil *Departamento de Medicina Veterinária Preventiva e Saúde Animal, Faculdade de Medicina Veterinária e Zootecnia, Universidade de São Paulo, Av. Corifeu de Azevedo Marques 2270, 05340-000 São Paulo, SP, Brasil ${ }^{* *}$ Departamento de Parasitologia, Instituto de Patologia Tropical e Saúde Pública, Universidade Federal de Goiás, Av. Delenda Rezende de Melo s/n,

Setor Universitário, 74001-970 Goiânia, GO, Brasil

The parasitic specificity of larval, nymph and adult Amblyomma cajennense on six different host species: Oryctolagus cuniculus, Rattus norvegicus, Gallus gallus domesticus, Anas platyrhynchus, Coturnix coturnix and Streptopelia decorata is described. In terms of the numbers of larvae and nymphs recovered, O. cuniculus was the best host species. The modal day for drop-off of larvae and nymphs was day three for the mammal hosts, but variable in the birds. We conclude that adult A. cajennense have a strong degree of specificity due to the fact that the tick failed to complete its life cycle on any of the evaluated hosts. The immature stages, on the other hand, showed a low level of specificity, most especially in the larval stage, indicating the existence of secondary hosts which probably serve as dispersers in the wild. The results also indicated a variable drop-off rhythm for larvae and nymphs in two periods, diurnal (6-18 hr) and nocturnal (18-6 hr), which differed depending upon the host.

Key words: Amblyomma cajennense - drop-off periodicity - host specificity

The genus Amblyomma has approximately 100 described species, 33 of which are found in Brazil (Aragão \& Fonseca 1961). Among these, Amblyomma cajennense (Fabricius, 1787) is restricted to the Americas, from the southwestern United States to Argentina (Robinson 1926). It is an important species in terms of public health. It parasitizes domestic animals and acts as a vector of Rickettsia ricketsii (Travassos \& Valejo-Freire 1944) and, experimentally at least, Cowdria ruminantium and Erhlichia bovis to cattle (Massard 1984).

A. cajennense is a three host tick occurring mainly on equids, but can also be found on a wide range of other hosts (Rohr 1909, Linardi et al. 1987, 1991a, b). Smith (1974b) emphasized the importance of determining the role of secondary hosts in the maintenance of its biological cycle in the wild and the possibility of the dispersion of immature stages by birds and wild and domestic mammals. An understanding of the biology and ethology of

This investigation was supported by CAPES and CNPq. ${ }^{+}$Corresponding author. Fax: +55-31-499.2080

Received 10 July 1997

Accepted 18 March 1998 the parasitic and free-living stages is vital for the establishment of control procedures for this important ectoparasite species.

The project analyzed $A$. cajennense host specificity on six different domesticated species and recorded the drop-off periodicity of the parasitic instars and the percentage recovery for each stage. This study was supported and concluded in the Ectoparasite Laboratory of the Department of Veterinary and Preventative Medicine of the Veterinary School of the Federal University of Minas Gerais, Belo Horizonte, during the period of May 1996 to February 1997.

\section{MATERIALS AND METHODS}

The species used for experimental infestation with A. cajennense were the following: domestic rabbits (Oryctolagus cuniculus), laboratory rats (Rattus norvegicus), domestic fowl (Gallus gallus domesticus), mallard ducks (Anas platyrhynchus), Italian quails (Coturnix coturnix) and African doves (Streptopelia decorata). These species were chosen due to the ease with which they can be obtained and maintained in the laboratory.

For this experiment, 13 mature fed $A$. cajennense females were collected from horses in 
May 1996, from the Fazenda Modelo, municipality of Pedro Leopoldo, Minas Gerais, Brazil. They were maintained in an incubator at $27^{\circ} \mathrm{C}$, and a relative humidity above $80 \%$. Thirty days after the oviposition, the eggs were separated, weighed and placed in specially-designed syringes (see Leite 1988 ) in groups of approximately 500 eggs. Those groups which showed an eclosion rate of more than 95\% were used for the tests.

Six individuals of each of the host species were used in the study of the larval phase. They were all young, immature and, for each species, similar in age and color and of the same sex. Each one received an infestation load of approximately 500 larvae which had been subjected to a period of fasting ranging from 50 to 70 days (Olivieri \& Serra Freire 1984a). To give the larvae the opportunity to fix themselves on the host, the animals were restrained for at least $2 \mathrm{hr}$ in a PVC tube closed with gauze at each end. Following this, they were placed in individual cages of galvanized wire and wood that was painted white. Each cage was surrounded by double-sided adhesive tape. The inoculation were always carried out between 5 to $6 \mathrm{pm}$.

The parasitic period and the drop-off rhythm of the larvae were evaluated daily. The detached larvae were collected at $6 \mathrm{hr}$ and $18 \mathrm{hr}$, and were subsequently placed in syringes in a incubator in order to provide them optimum conditions for further development. The initial and final ecdyses were recorded.

This methodology was repeated for the nymphal and adult stages, although always with a new group of hosts, all without prior tick infestation experiences and with the same characteristics as mentioned above for the larval stage experiment. The infestation load for nymphs was 150 and that for the adults five pairs per animal.

Statistical treatment of the data involved the use of the chi-squared test to look for any association between periodicity of the larval and nymphal drop-off and the host species, and the KruskalWallis test was used to examine if the number of engorged parasites and the number dropping off varied between host species. The 5\% significance level was used in all cases.

\section{RESULTS}

The attachment period for the majority of the larvae and nymphs was less than $12 \mathrm{hr}$. The period of parasitism for these immature stages was variable: in the rabbits it was 3-7 days for both developmental stages: in the quail 3-6 days for larvae and 4-5 days for the nymphs; in the pigeons 3-6 days for larvae and 3-7 days for nymphs; and in the rats 3-8 days for larvae and 3-4 days for nymphs (Tables I, II).

The modal drop-off day for the larvae and nymphs of $A$. cajennense feeding on rabbits and Norway rats was on the 3rd day. In pigeons and ducks it was one day later for both larvae and nymphs. The modal drop-off for quails was on the 3rd day for the larvae and the 4th day for the nymphs. For the fowl, the reverse was true; the 4th day was modal for the drop-off of the larvae, and the 3rd day for the nymphs (Tables I, II, Figs 1,2).

TABLE I

Total number and recovery rate, mean numbers per host, temporal distribution of drop-off and the parasitism period of larvae of Amblyomma cajennense on six different host species

\begin{tabular}{|c|c|c|c|c|c|c|c|}
\hline $\operatorname{Host}^{a}$ & $\begin{array}{l}\text { Modal } \\
\text { day }\end{array}$ & $\begin{array}{l}\text { Total larvae } \\
\text { recovered }(\%)\end{array}$ & $\begin{array}{l}\text { Mean/ho } \\
\text { and rang }\end{array}$ & & $\begin{array}{l}\text { Larvae } \\
\text { recovered } \\
6-18 \mathrm{hr} \\
\end{array}$ & $\begin{array}{l}\text { Larvae } \\
\text { recovered } \\
18-6 \mathrm{hr} \\
\end{array}$ & $\begin{array}{l}\text { Parasitism } \\
\text { period (days) } \\
\text { Min-Max }\end{array}$ \\
\hline Oryctolagus cuniculus & 3 & $\begin{array}{l}2,527 \\
(84.2)\end{array}$ & 421.7 & $\mathrm{a}$ & 1,335 & 1,192 & $3-7$ \\
\hline Anas platyrhynchus & 4 & $\begin{array}{l}1,694 \\
(56.5)\end{array}$ & 282.3 & $\mathrm{~b}$ & 1,197 & 497 & $3-6$ \\
\hline Gallus gallus domesticus & 4 & $\begin{array}{l}1,365 \\
(45.5)\end{array}$ & 227.5 & $\mathrm{~b}$ & 765 & 600 & $3-7$ \\
\hline Rattus norvegicus & 3 & $\begin{array}{c}498 \\
(16.6)\end{array}$ & 83.0 & $\mathrm{c}$ & 346 & 152 & $3-8$ \\
\hline Coturnix coturnix & 3 & $\begin{array}{l}254 \\
(8.5)\end{array}$ & 42.3 & $\mathrm{c}$ & 157 & 97 & $3-6$ \\
\hline Streptopelia decorata & 4 & $\begin{array}{c}232 \\
(7.7)\end{array}$ & 38.6 & $\mathrm{c}$ & 99 & 133 & $3-6$ \\
\hline
\end{tabular}

$a$ : six individuals of each species were inoculated with an individual infestation load of 500 larvae; $b$ : different letters indicate statistically significant differences. 


\section{TABLE II}

Total number and recovery rate, mean numbers per host, temporal distribution of drop-off and the parasitism period of nymphs of Amblyomma cajennense on six different host species

\begin{tabular}{|c|c|c|c|c|c|c|c|}
\hline \multirow{2}{*}{$\begin{array}{l}\text { Host }^{a} \\
\text { Oryctolagus cuniculus }\end{array}$} & \multirow{2}{*}{$\begin{array}{r}\begin{array}{l}\text { Modal } \\
\text { day }\end{array} \\
3\end{array}$} & \multirow{2}{*}{$\begin{array}{l}\text { Total nymphs } \\
\text { recovered }(\%) \\
803 \\
(89.2)\end{array}$} & \multicolumn{2}{|c|}{$\begin{array}{l}\text { Mean/host } \\
\text { and range }\end{array}$} & \multirow{2}{*}{$\begin{array}{l}\text { Nymphs } \\
\text { recovered } \\
6-18 \mathrm{hr}\end{array}$} & \multirow{2}{*}{$\begin{array}{l}\text { Nymphs } \\
\text { recovered } \\
18-6 \mathrm{hr} \\
246\end{array}$} & \multirow{2}{*}{$\begin{array}{l}\text { Parasitism } \\
\text { period (days) } \\
\text { Min-Max } \\
3-7\end{array}$} \\
\hline & & & 133.8 & $\mathrm{a}$ & & & \\
\hline Streptopelia decoratas & 4 & $\begin{array}{c}10 \\
(1.1)\end{array}$ & 1.7 & $\mathrm{~b}$ & 10 & - & $3-4$ \\
\hline Coturnix coturnix & 4 & $\begin{array}{c}18 \\
(2.0)\end{array}$ & 3.0 & $\mathrm{cb}$ & 10 & 8 & $4-5$ \\
\hline Gallus gallus domesticus & 3 & $\begin{array}{c}34 \\
(3.8)\end{array}$ & 5.7 & ce & 20 & 14 & $3-4$ \\
\hline Anas platyrhynchus & 4 & $\begin{array}{c}161 \\
(17.9)\end{array}$ & 26.8 & $\mathrm{~d}$ & 73 & 88 & $3-7$ \\
\hline Rattus norvegicus & 3 & $\begin{array}{c}53 \\
(5.9)\end{array}$ & 8.8 & $\mathrm{e}$ & 43 & 10 & $3-4$ \\
\hline
\end{tabular}

$a$ : six individuals of each species were inoculated with an individual infestation load of 150 nymphs; $b$ : different letters indicate statistically significant differences.

Oryctolagus cuniculus

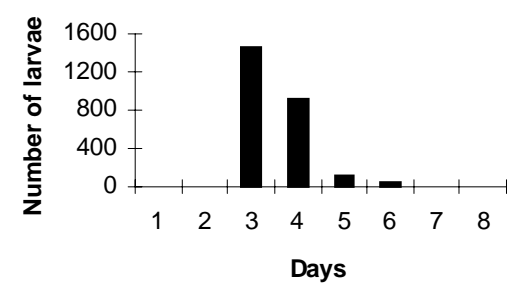

Gallus gallus domesticus

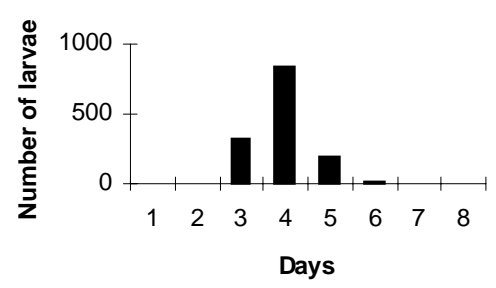

Coturnix coturnix

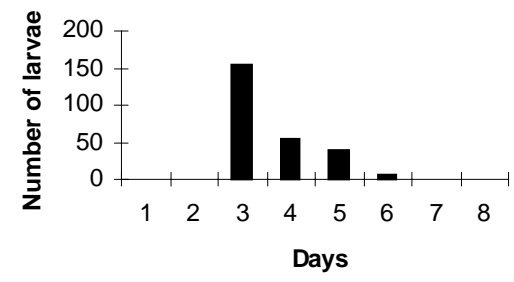

Rattus norvegicus

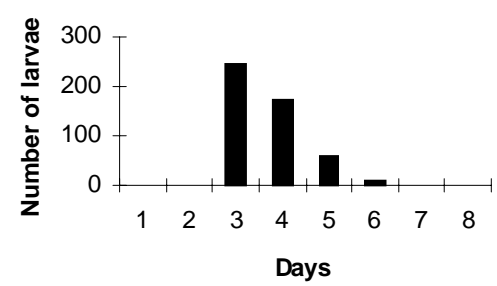

Anas platyrhynchus

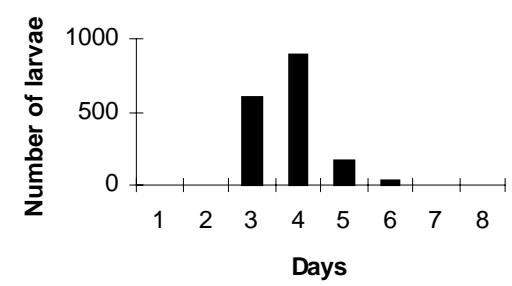

Streptopelia decorata

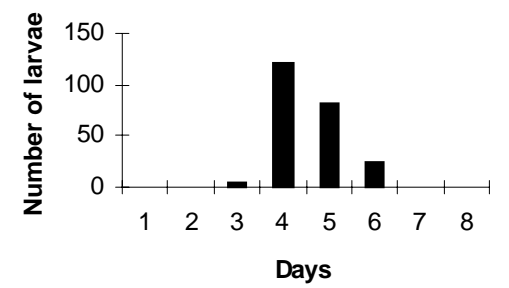

Fig. 1: number of engorged larvae recovered per day dropping off six individuals of each of six host species inoculated with 500 larvae of Amblyomma cajennense. 
Oryctolagus cuniculus

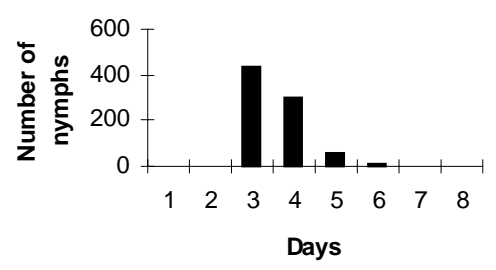

Gallus gallus domesticus

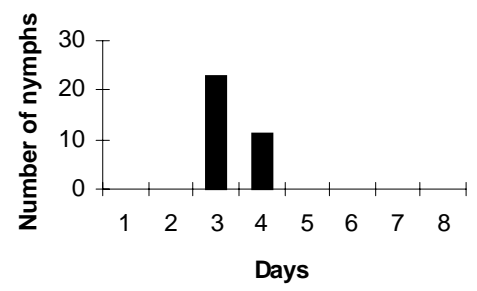

Coturnix coturnix

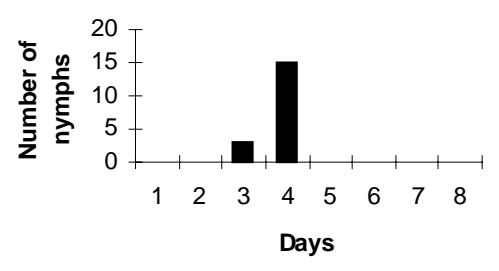

Rattus norvegicus

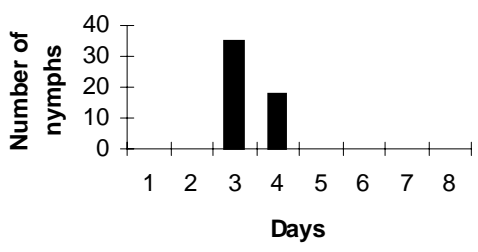

Anas platyrhynchus

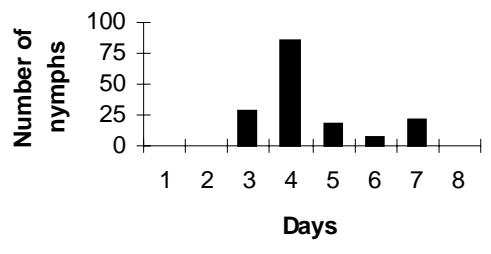

Streptopelia decorata

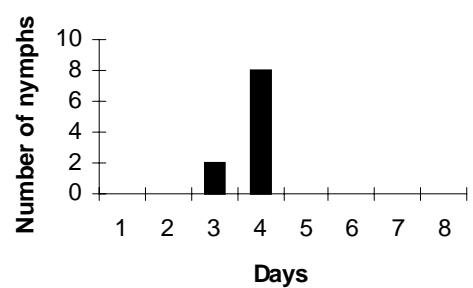

Fig. 2: number of engorged nymphs recovered per day dropping off six individuals of each of six host species inoculated with 150 nymphs of Amblyomma cajennense.

The greatest number of larvae were recovered from the hosts, rabbits indicating that they were the best hosts in terms of the intensity of parasitism (Tables I, II). They were followed by ducks, fowl, rats, quail and pigeons. There was no statistically significant difference in the pairwise comparisons of ducks-fowl ( $p>0.30)$, quail-rats $(p>0.40)$, quail-pigeons ( $p>0.60)$ and pigeons-rats $(p>0.15)$ for the larval phase. For the nymphal phase, recovery was found to be highest from rabbits, with no statistically significant difference between quail and pigeons ( $>0.15)$, quail and fowl $(p>0.50)$, and fowl and rats $(p>0.30)$. There was statistical evidence that drop-off periodicity (nocturnal, 18 to $6 \mathrm{hr}$, as opposed to diurnal, 6-18 hr) for the engorged larvae and the nymphs of $A$. cajennense differed between the host species.

The study of the adult phase demonstrated a poor incidence of parasitism. A mere five females, only partially engorged, were obtained from just two of the six rabbits infested. Of these, only two produced eggs (497 and 83, respectively), which were non-viable. This demonstrated that the biological cycle of A. cajennense coud not be main- tained on any of the host species studied.

\section{DISCUSSION}

The parasitism period and drop-off rhythm for both larvae and nymphs recorded in this study contrast with the findings of a number of other authors who have studied the biological cycle of $A$. cajennense in rabbits (Hooker et al. 1912, Smith 1974a, Olivieri \& Serra Freire 1984a, b, Serra Freire \& Olivieri 1992). Except for rats (Smith 1974a, b), A. cajennense parasitism on the other host species has never been studied before. Hoogstraal and Aechlimann (1982) commented that about $10 \%$ of the World's tick species infect domestic birds and mammals. A number of Amblyomma and Ixodes species have been collected from various hosts in both immature and adult stages. Of the 102 species of Amblyomma, 37 feed on reptiles and about 20, in both larval and nymphal stages, have been found to feed on birds. Mammals are more commonly the hosts to these ticks than birds and reptiles. Mammals are hosts to at least one species of each genus. Amongst the mammalian orders, rodents comprise the group having more tick parasites than any other; 
immature stages of the ticks having been recorded feeding on more than 300 species (Oliver 1989). Although the current literature emphasizes the importance of rodent hosts, in this study $R$. norvegicus was one of the species with the smallest recovery rates for larvae and nymphs. Some studies of ectoparasites in wild rodent populations in Brazil have also shown very low parasitism by ixodid ticks, $A$. cajennense included (Aragão \& Fonseca 1961, Linardi et al. 1987, 1991a, b). Much more research is required to improve our understanding of tick life cycles and their hosts, especially considering the ever increasing environmental changes resulting from agricultural practices which favor some species, and undoubtedly alter or even extinguish ancient tickhost associations (Hoogstraal \& Aechlimannn 1982).

Host activity and the epidemiological factors connected with the environment (temperature, humidity and photoperiod) appear to act differently on different species in determining the drop-off period. Not all show a single pattern (diurnal or nocturnal), and periodicity may vary at different stages of the life cycle (Oliver 1989, Sonenshine 1993). This was observed in our study for both the pigeons and the ducks (Tables I, II). The drop-off period was consistent for the other hosts and independent of their circadian rhythms.

We conclude that there is a certain degree of host specificity for adult $A$. cajennense. In none of the host species tested did this ixodid tick complete its biological cycle. Interestingly, specificity was lower in the immature stages, and lower in the larval stage than in the nymphal. It is evident that a variety of smaller animals can serve as hosts for A. cajennense and may serve as a mode of dispersal. This is supported by the work of Smith $(1974 a, b)$ who recorded that larvae and nymphs of this species feed well on rodents and lagomorphs, and indicated that small mammals may be important for the maintenance of $A$. cajennense in infested areas. Although Smith did not capture any wild hosts infested by this species, he emphasized the need for more studies to determine the role they play as secondary hosts. Studies of this sort, which examine biological and ecological parameters of a tick's life cycle contribute to the development of more rational control of this tick species.

\section{ACKNOWLEDGMENTS}

To Professors Ivan Sampaio, Horácio Faccini and David Evans for their criticisms and useful suggestions, and to Sônia Rita do Nascimento for care of the animals used in the experiments.

\section{REFERENCES}

Aragão H, Fonseca FOR 1961. Notas de Ixodologia.VIII. Mem Inst Oswaldo Cruz 59: 115-129.

Hoogstraal H, Aechlimann A 1982. Tick host specific- ity. Bull Societe Entomol Suisse 55: 5-32.

Hooker WA, Bishop FC, Wood HP 1912. The Life History and Bionomics of Some North American Ticks, US Dept Agri Bur Entomol Bull no 106, Washington, $167 \mathrm{pp}$.

Leite RC 1988 Boophilus microplus (Canestrini, 1887): Susceptibilidade, Uso Atual e Retrospectivo de Carrapaticidas em Propriedades das Regiões Fisiogeográficas da Baixada do Grande Rio e Rio de Janeiro, uma Abordagem Epidemiológica, $\mathrm{PhD}$ Thesis, UFRRJ, Itaguaí, Rio de Janeiro,151 pp.

Linardi PM, Teixeira VP, Botelho JR, Ribeiro LS 1987. Ectoparasitos de roedores em ambientes silvestres do município de Juiz de Fora, Minas Gerais. Mem Inst Oswaldo Cruz 82: 137-139.

Linardi PM, Botelho JR, Rafael JA, Valle CMC, Cunha A, Machado PAR 1991a. Ectoparasitos de pequenos mamíferos da Ilha de Maracá, Roraima, Brasil. 1. Ectoparasitofauna, registros geográficos e de hospedeiros. Acta Amazonica 21: 131-140.

Linardi PM, Botelho JR, Ximenez A, Padovani CR 1991b. Notes on ectoparasites of some small mammals from Santa Catarina State, Brazil. J Med Entomol 28: 183-185.

Massard CA 1984. Ehrlichia bovis (Donatien \& Lestoquard, 1936). Diagnóstico, Cultivo "in Vitro"e Aspectos Epidemiológicos em Bovinos no Brasil, PhD Thesis, UFRRJ, Itaquaí, Rio de Janeiro, 113 pp.

Oliver JH 1989. Biology and systematics of ticks (Acari: Ixodida). Ann Rev Ecol Syst 20: 397-430.

Olivieri JA, Serra Freire NMS 1984a. Estádio larval do ciclo biológico de Amblyomma cajennense. Arq Univ Fed Rur RJ 7: 139-148.

Olivieri JA, Serra Freire NMS 1984b. Estádio ninfal do ciclo biológico de Amblyomma cajennense. Arq Univ Fed Rur RJ 7: 149-156.

Robinson LE 1926. The Genus Amblyomma, Cambridge Univ Press, Great Britain, 301 pp.

Rohr, CJ 1909. Estudos sobre Ixodidae do Brasil. Rio de Janeiro. Inst Oswaldo Cruz p. 110-117.

Serra Freire NM, Cunha DW 1987. Amblyomma cajennense: comportamento de ninfas e adultos como parasitos de bovinos. Rev Bras Med Vet 9: 100-103.

Serra Freire NM, Olivieri JA 1992. Estádio adulto do ciclo de Amblyomma cajennense. Arq Fac Vet UFRGS 20: 224-234.

Smith MW 1974a. Some aspects of ecology and lifecycle of Amblyomma cajennense (Fabricius, 1787) in Trinidad and their influence on tick control measures. Ann Trop Med Parasitol 69: 121-129.

Smith MW 1974b. A survey of the distribution of the ixodid ticks Boophilus microplus (Canestrini, 1888) and Amblyomma cajennense (Fabricius, 1787) in Trinidad and Tobago and the possible influence of the survey results on planned livestock development. Trop Agric (Trinidad) 51: 559-567.

Sonenshine DE 1993. Biology of Ticks, Vol. 2, Oxford University Press, Oxford, 465 pp.

Travassos J, Valejo-Freire J 1944. A criação artificial de Amblyomma cajennense para o preparo de vacina contra a febre maculosa. Mem Inst Butantan 18: 145235 . 
Host Specificity of Amblyomma cajennense - Cristina ML Lopes et al. 